\title{
Selection of design alternatives in the formation of energy-saving programs at the enterprises of the mining and metallurgical complex of Ukraine
}

\author{
Ivan Trifonov ${ }^{1}$, Petro Sankov ${ }^{2 *}$, Kostiantyn Dikariev², and Olha Kapshuk ${ }^{2}$ \\ ${ }^{1}$ Financial University, 49 Leningradskiy Ave., 125993 Moscow, Russia \\ ${ }^{2}$ Prydniprovs'ka State Academy of Civil Engineering and Architecture, 24a Chernyshevskoho St., \\ 49600 Dnipro, Ukraine
}

\begin{abstract}
In the article, a method is proposed for making management decisions in the conditions of uncertainty when choosing project alternatives under the energy saving program at an enterprise of the mining and metallurgical complex (MMC) of Ukraine. The purpose of the article is to develop project practice for improving the feasibility of management decisions in the implementation of energy saving programs of the MMC of Ukraine, using the value criteria from the point of view of parties concerned at a ratio of the expected project results and resource constraints. At the same time, there is a need to measure the extent to which a particular project contributes to achieving a program goal. Therefore, the list of value criteria of the project results in the work was turned into an absolute measurement scale; this allowed evaluating each alternative project at the stage of developing a program to minimize the consumption of fuel and energy resources necessary for the production of products (services) of preset quality, with account of the degree of concerned parties' satisfaction, limitedness of organization resources and risk factors. In the process of research, the following research methods were applied: survey, system analysis, and set theory. Based on the results obtained, it has been revealed that most of the problems in implementing the energy saving strategy are related to payback issues and a decrease in the loss of fuel and energy resources per $1 \mathrm{UAH}$ of finished products. The overall assessment when ranking the goals of the energy saving program ranges from 1.2 to 2.6 , which, in turn, is a prerequisite for the use of value-based management in the program formation.
\end{abstract}

\section{Introduction}

The development of business and the economy as a whole, meeting the needs of the Ukrainian population is determined by the functioning of a number of basic industries, as well as the rational (efficient) use of resources at industrial enterprises of the country. The level of energy development reflects the level of the productive forces development of

\footnotetext{
${ }^{*}$ Corresponding author: petrsankov5581@gmail.com
} 
society, the possibility of scientific and technological progress and the living standards of the population. Ukraine has a low level of self-sufficiency in energy resources and is an energy-deficient state. Energy demand is provided by its own resources by only $53 \%$.

On the other hand, the energy intensity of Ukraine's gross domestic product is three to five times higher than in the developed countries of Western Europe. The energy saving potential of Ukraine is $45 \%$ of the current energy consumption volume. Mining and smelting complex is the largest consumer of energy resources. The largest consumers of fuel and energy resources in the mining and smelting industry are metallurgical (about $75 \%$ ) and coke-chemical (about 18\%) enterprises [1].

The most priority direction of the industrial policy of Ukraine is energy saving and energy efficiency in all spheres and sectors of the economy. The significant role of the mining and metallurgy sector in ensuring the state's competitiveness on the world market determines the increase in the internal requirements for the activities of each enterprise in the industry, primarily in energy management.

The specifics of metallurgical production require new approaches to the formation of an energy saving management system at the enterprises of the MMC of Ukraine. Mining and metallurgical complex of Ukraine is the basis of the state economy. The miningmetallurgical complex had and is of major economic and socio-political importance for Ukraine.

\section{Relevance}

In the modern conditions of the development of market relations in Ukraine, there is an urgent need to increase the competitiveness of enterprises through various types of changes (restructuring, reforming, modernization, reengineering, etc.). At the same time, enterprises face the problem of forming sustainable competitive advantages on the basis of a more complete strategic transformation of the organization's capabilities with limited resources (labor, financial and material). It should be borne in mind that the embodiment of the concept of energy conservation requires highly skilled and tough management of all available resources of the enterprise.

The practical implementation of the concept should cause steady positive short-term and long-term changes in the activities of the enterprise, which will result in an increase in the market value of equity and the value of its shares. As is known, the organization's strategic goals are achieved through the implementation of projects (programs, project portfolios). One of the key points of program-based management is the decision-making process for selecting project alternatives within the program.

Energy policy, which involves a long-term vision and improvement of environmental performance. Energy strategy involves a systematic approach, with a roadmap to achieve the goals of energy policy. However, the standards do not provide clear recommendations for the implementation of an energy strategy or policy in organizations [2].

There is a need for systematic energy asset management $[3,4]$, by reducing carbon emissions, as well as improving safety [5-7].

Trachuk and Linder note that today it is possible to obtain cheap electric and thermal energy in connection with the use of energy-efficient solutions based on distributed generation technologies [8]. Böttcher and Müller say that for the system to increase energy efficiency, organizations need to combine the vision of the energy management strategy developed in the standards with their own organizational structure [5]. At the same time, the development of processes, strategies and structures of the enterprise should be amended taking into account innovative approaches and stakeholders [9].

Finnerty N., SterlingR., Contreras S., Coakley D., Keane M. for energy-intensive multinational production formulated a vision and methodological approach to corporate 
energy policy and strategy in support of the energy management system [10].

A risk-based approach to quantify the effectiveness of changes in resource constraints and the ranking of the objectives of the energy saving program, taking into account risk factors for energy-intensive enterprises in Ukraine, was proposed in [11]. A similar approach for Chinese enterprises is given in [12].

It should be noted that one of the main problems that is outlined in these works is the difficulty of determining the priority of projects in enterprises' energy saving programs, taking into account value propositions and risk events, which, in turn, is a prerequisite for developing a method for selecting project alternatives when developing programs energy saving at the enterprises of the mining and smelting complex of Ukraine.

\section{Results and discussion}

The program within the framework of the energy saving strategy assumes that the planned changes should be implemented within the framework of certain limitations on terms, cost, quality and value from the point of view of the enterprise and the maximum number of stakeholders. The existence of these restrictions imposes special requirements on the methods of project and program management, in particular, the requirement to concentrate powers and responsibility for the effective implementation of the program, both for managers and for project teams. At the same time, the program becomes the center of costs and profits of the organization, which requires special attention to accounting for human, material and financial resources and building a system of motivation, which is based on the results of specific projects.

As noted earlier, the strategy is implemented in the enterprise through the program, therefore this activity can be safely considered program-oriented. At the same time, the program approach in management can be considered as a full-fledged methodological and organizational toolkit.

The goal of the program within the framework of the energy saving strategy in this work is to consider a set of interrelated projects, the implementation of which will allow reducing the consumption of fuel and energy resources or increasing the efficiency of their use. The research algorithm consisted of several stages (Fig. 1).

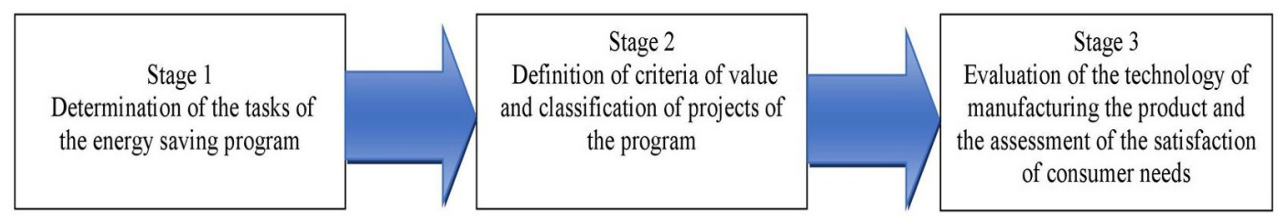

Fig. 1. Stages of research methodology.

For energy-intensive enterprises, the programs of energy saving, quality and ecology are particularly relevant in the framework of the strategy for energy saving.

In particular, energy conservation programs within the framework of an organization's strategy have significant differences in scale, duration, complexity, cost, etc. Practice proves that successful implementation of programs within the framework of the established budget, in accordance with the technical requirements of quality is possible only within a formalized environment and is supported by the project and program methodology. As such an environment, it is proposed to consider the program management system, which is a mechanism for developing and implementing value-oriented solutions at all levels of project and program management at the enterprise. This mechanism will ensure the 
effectiveness of management and coordination of the work of the energy saving program on the basis of a unified methodological framework.

At the first stage of the survey, 15 top managers of Kryvorizhstal (MittalStiel Kryvyi Rih) were surveyed.

The management decision-making process as the choice of the most rational (best) project alternative from a certain universal set of project alternatives can occur with varying degrees of awareness of the decision maker.

If information about the real situation, on the basis of which different design alternatives are compared, can be described in the form of a preference relation on a set of alternatives [13].

Consider this relationship and its properties. Suppose that, on the basis of information received from the decision maker, on the set of feasible design alternatives $-X$ a clear nonstrict preference relation $-R$ is introduced. This means that for any pair of project alternatives $(x, y)$, one of the following statements can be made:

$-x$ maybe not worse $y$, that is $x \succcurlyeq y$ or $(x, y) \in R$;

$-y$ maybe not worse $x$, that is $y \succcurlyeq x$ or $(y, x) \in R$;

$-x$ and $y$ they are incomparable, that is $(y, x) \notin R,(x, y) \notin R$.

Such information allows us to narrow down the class of rational choices by including in it only those project alternatives that are not dominated by any of the project alternatives from the set $-X$.

In order to define non-dominated design alternatives, we introduce a strict preference relation $R_{S}$, corresponding to non-strict preference $R$, as well as an attitude of indifference $R_{J}$. Imagine that the project alternative strictly better than project alternative $y$, if at the same time, $x \geq y$, a $y \geq x$, that is $(x, y) \in R,(y, x) \notin R$. The totality of all such pairs $(x, y)$ and is called a strict preference attitude $R_{S}$ on set $X$.

If a $(x, y) \in R_{S}$, then, the project alternative $x$ dominates the project alternative $y$ (spelled $x>y$ ). Project Alternative $x \in X$ we call non-dominated on the set $X$ with a given ratio $R_{S}$, if a $(y, x) \notin R_{S}$ for any project alternative $y \in X$. In other words, if $x$ - not dominated by project alternative then on set $X$ there are no project alternatives $y$, which would dominate $x$.

When modeling real systems (programs, portfolios, projects, works), situations may arise when the decision maker does not have information about the relationship of preferences between all or some of the project alternatives, and he can only assess the degree of implementation of one or another between pairs of project alternatives in the form of interval $(0,1)$. In this case, you can enter a fuzzy preference relationship.

Consider the use of a fuzzy preference relation and a set of non-dominated alternatives in the problem of rational choice in the presence of several criteria. Since the set of clearly non-dominated alternatives plays a significant role in rational choice problems, since it can be considered as a clear solution to an unclearly formulated problem.

Consider the use of a fuzzy preference relation and a set of non-dominated alternatives in the problem of rational choice in the presence of several criteria.

Let there be a situation when any of the criteria $j$ set in the form of clear utility functions $f_{i}: X \rightarrow R^{(1)}$. The value $f_{i}(x)$ describes (sets) the usual (clear) preference relationship on a variety of alternatives $X$ kind of $R_{j}=\left\{(x, y): f_{j}(x) \geq f_{j}(y), x, y \in X\right\}$.

The challenge is to choose an alternative $x_{0}$, which would have the highest scores for all criteria (features). And so, the choice of alternative should be considered rational in this 
case $x_{0} \in X$, which has the property:

$$
f_{j}\left(x_{0}\right) \geq f_{j}(y), \forall y \in X, j=1, m .
$$

Such alternatives are called effective, and the solution to this choice problem is the set of all effective alternatives.

To solve the formulated problem of a multi-criteria choice, it is necessary to choose the appropriate method of convolution of many criteria (vector criterion) into a scalar one.

1. One of the most common ways of convolving criteria is to use an intersection. Let be $Q_{1}=\bigcap_{i=1}^{m} R_{1}$. Then the set of effective alternatives in the set $X$ with a preference attitude $Q_{1}$ matches many effective alternatives for a set of functions $f_{i}(x)$.

Thus, instead of choosing relations, to find a set of effective alternatives $R_{j}, j=\overline{1, m}$ use their intersection $Q_{1}$ and find a multitude of non-dominated alternatives for a fuzzy ratio of preference $Q_{1}$.

Denote by $\mu_{j}(x, y)$ fuzzy preference membership function. Obviously:

$$
\mu_{j}(x, y)=\left\{\begin{array}{l}
1, \text { if } \mathrm{a}(x) \geq f_{j}(y), \text { or }(x, y) \in R_{j} \\
0,(x, y) \in R_{j} .
\end{array}\right.
$$

Then their intersection - fuzzy relation preference $Q_{1}$ is membership function:

$$
\mu_{Q_{1}}(x, y)=\min \left\{\mu_{1}(x, y), \mu_{2}(x, y), \ldots, \mu_{m}(x, y)\right\} .
$$

Such a convolution of criteria is similar to a convolution:

$$
F(x)=\min _{j} \omega_{j} f_{j}(x)
$$

used in multiobjective decision making.

The numbers $\omega_{j}$ at $(3)-$ there are the relative weights of the relevant criteria. In convolution (2) obviously $\omega_{j}=1, \forall j=\overline{1, m}$. If $\omega_{j} \neq 1$, that

$$
\mu_{Q_{1}}(x, y)=\min \left\{\omega_{1} \mu_{1}(x, y), \omega_{2} \mu_{2}(x, y), \ldots, \omega_{n} \mu_{n}(x, y)\right\},
$$

meaning attitude $Q_{l}$ is no longer reflective.

2. We introduce the convolution of the original relations $\left\{R_{j}\right\}$ as a sum:

$$
Q_{2}=\sum_{j=1}^{m} \omega_{j} f_{j}(x), \text { where } \sum_{j=1}^{m} \omega_{j}=1, \omega_{j} \geq 0 .
$$

It corresponds to the membership function of the form $\mu_{Q_{2}}(x, y)=\sum_{j=1}^{m} \omega_{j} \mu_{j}(x, y)$.

Note that the resulting fuzzy preference relation $Q_{2}$ reflexively, since all initial fuzzy preference relations $R_{j}$ are reflective.

Consider the case when all the original relationships are equally important, that is, $\omega_{j}=\frac{1}{m}, j=\overline{1, m}$. Construct a fuzzy subset of non-dominated alternatives $Q_{2}^{n d}$, using the previously introduced definitions: 


$$
\mu_{Q_{2}}^{n d}(x)=1-\frac{1}{m} \sup \left\{\sum_{j=1}^{m} \mu_{j}(y, x)-\mu_{j}(x, y)\right\}, x \in X .
$$

Denote by $X_{1}^{\text {cnd }}$ a subset of clearly non-dominated alternatives of the set $\left\{X, Q_{1}\right\}$, and through $X_{2}^{\text {cnd }}$ respectively, a subset of clearly non-dominated alternatives of the set $\left\{X, Q_{2}\right\}$. Can show, $X_{2}^{\text {cnd }} \subseteq X_{1}^{\text {cnd }}$.

We investigate the properties of alternatives from the set $Q_{2}^{\text {nd }}$. Obviously function $\mu_{Q_{2}}^{n d}(x)$ acquires only values of the form $\frac{k}{m}$, where $k$ is natural number, $k<m$. Let for some alternative $x^{\prime} \mu_{Q_{2}}^{n d}\left(x^{\prime}\right)=\frac{k}{m}$. According to (4), this means that

$$
\sup _{y}\left\{\sum_{j=1}^{m} \mu_{j}\left(y, x^{\prime}\right)-\mu_{j}\left(x^{\prime}, y\right)\right\}=m-k \text { or }\left\{\sum_{j=1}^{m} \mu_{j}\left(y, x^{\prime}\right)-\mu_{j}\left(x^{\prime}, y\right)\right\} \leq m-k
$$

for anyone $y \in X$. Since the terms of the sum in (4) acquire only the values 0 or \pm 1 , then from (7) it follows that the difference between the number of members of this sum, equal to +1 , and the number of members equal to -1 , does not exceed $m-k$ at any $y \in X$. This can be explained as follows. Let be $P(y, x)$ is number of functions $f_{j}$ from a given set, for each of which is an alternative $y$ strictly better $x$, and $q(y, x)$ - number of functions $f_{j}$, for which alternative $x$ strictly better $y$. If $\mu_{Q_{2}}^{n d}\left(x^{\prime}\right)=\frac{k}{m}$, that $P\left(y, x^{\prime}\right)-q\left(y, x^{\prime}\right) \leq m-k$ at any $y \in X$. So the function $\mu_{Q_{2}}^{n d}(x)$ orders alternatives by degree of their non-dominance.

Further, it is advisable to look for intersections of sets $Q_{1}^{\text {nd }}, Q_{2}^{\text {nd }}$, and find $Q_{n d}=Q_{1}^{\text {nd }} \cap Q_{2}^{\text {nd }}$ and the corresponding membership function $\mu_{n d}(x)=\min \left\{\mu_{Q_{1}}^{n d}(x), \mu_{Q_{2}}^{n d}(x)\right\}$. On set $Q_{n d}$ it is necessary to find alternatives with the maximum degree of non-dominance. This will be the best choice. The algorithm for selecting design alternatives in the presence of many criteria for optimality (fuzzy preference relations) has the following steps:

1. Let on the universal set of alternatives $X$ preference relationships are set $R_{1}, R_{2}, \ldots, R_{m}$ (clear or fuzzy) with membership functions $\mu_{j}(x, y)$, and $\omega_{j}, j=\overline{1, m}-$ weights of the corresponding relationship. We build the convolution of relations $R_{1}, R_{2}, \ldots, R_{m}$ in the form of an intersection $Q_{1}=\bigcap_{j=1}^{m} R_{j}$, with accessory function $\mu_{Q_{1}}(x, y)=\min \left\{\mu_{1}(x, y), \mu_{2}(x, y), \ldots, \mu_{m}(x, y)\right\}$.

2. Define a set of non-dominated alternatives. $Q_{1}^{\text {nd }}$ on set $\left(X, Q_{1}\right)$ $\mu_{Q_{1}}^{n d}(x)=1-\sup _{y \in X}\left\{\mu_{Q_{1}}(x, y)-\mu_{Q_{1}}(y, x)\right\}$.

3. Using the convolution criteria in the form of a sum, we construct a fuzzy preference relation $Q_{2} \mu_{Q_{2}}(x, y)=\sum_{j=1}^{m} \omega_{j} \mu_{j}(x, y), \sum_{j=1}^{m} \omega_{j}=1, \omega_{j} \geq 0$. 
4. Find a fuzzy subset of non-dominated alternatives with respect to $Q_{2}$ $\mu_{Q_{2}}^{n d}(x)=1-\sup _{y \in X}\left\{\mu_{Q_{2}}(x, y)-\mu_{Q_{2}}(y, x)\right\}$.

5. Find the intersection of sets $Q_{1}^{\text {nd }}, Q_{2}^{\text {nd }}$, and the total number of non-dominated alternatives $Q_{n d}=Q_{1}^{n d} \cap Q_{2}^{n d}$ with accessory function $\mu_{n d}(x)=\min \left\{\mu_{Q_{1}}^{n d}(x), \mu_{Q_{2}}^{n d}(x)\right\}$.

6. Rational consider the choice of project alternatives from the set $X_{n d}=\left\{x^{*}: \mu_{n d}\left(x^{*}\right)=\sup \mu_{n d}\left(\begin{array}{l}x \\ x\end{array}\right), x \in X\right\}$.

7. So, the best should be considered the choice of alternatives from the set with the greatest degree of non-dominance. Consider the task, c expert data obtained at the enterprise of the MMC of Ukraine "Kryvorizhstal" (MittalStill Kryvyi Rih), Tables 1 and 2.

Table 1. Ranging energy saving objectives.

\begin{tabular}{|c|l|c|c|c|c|}
\hline No. & \multicolumn{1}{|c|}{$\begin{array}{c}\text { Objectives of the program } \\
\text { energy saving }\end{array}$} & Importance & Priority & $\begin{array}{c}\text { Future } \\
\text { meaning }\end{array}$ & $\begin{array}{c}\text { Overall } \\
\text { rating }\end{array}$ \\
\hline 1 & Payback < & 1.0 & 0.9 & 0.7 & 2.6 \\
\hline 2 & $\begin{array}{l}\text { The value of excess water costs } \\
\text { for 1 UAH. finished products }\end{array}$ & 0.8 & 0.7 & 0.6 & 2.1 \\
\hline 3 & $\begin{array}{l}\text { Compliance with the } \\
\text { technological regime }\end{array}$ & 0.4 & 0.4 & 0.5 & 1.3 \\
\hline 4 & $\begin{array}{l}\text { Reducing the loss of energy } \\
\text { resources by 1 UAH. finished } \\
\text { products }\end{array}$ & 0.4 & 0.6 & 0.2 & 1.2 \\
\hline 5 & $\begin{array}{l}\text { Reduction of accounts receivable } \\
\text { and the period of its return }\end{array}$ & 0.7 & 0.5 & 0.5 & 1.7 \\
\hline 6 & $\begin{array}{l}\text { Improving management } \\
\text { accounting systems }\end{array}$ & 1.0 & 0.4 & 0.3 & 1.7 \\
\hline
\end{tabular}

Table 2. Priorities and rating evaluation of project alternatives.

\begin{tabular}{|c|c|c|c|c|c|c|c|}
\hline Project Alternatives & 氧 & 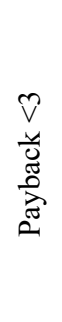 & 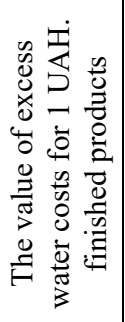 & 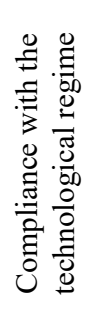 & 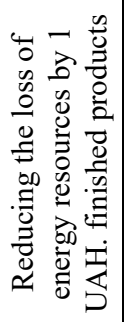 & 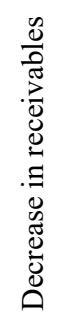 & 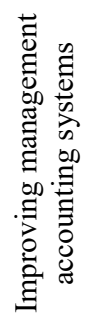 \\
\hline Weight criterion & & 2.6 & 2.1 & 1.3 & 1.2 & 1.7 & 1.7 \\
\hline $\begin{array}{l}\text { Introduction of } \\
\text { metering and } \\
\text { monitoring of } \\
\text { coolant losses }\end{array}$ & 55.7 & 7 & 5 & 2 & 2 & 2 & 9 \\
\hline $\begin{array}{l}\text { Preventive network } \\
\text { testing. Elimination } \\
\text { of breakthroughs }\end{array}$ & 51.2 & 8 & 7 & 4 & 1 & 2 & 0 \\
\hline $\begin{array}{l}\text { Replacing physically } \\
\text { worn insulation. } \\
\text { Insulation of pipe } \\
\text { insulation }\end{array}$ & 48.4 & 7 & 0 & 8 & 10 & 3 & 0 \\
\hline
\end{tabular}


Based on the data in Tables 1 and 2, the task of choosing the best design alternative is formulated as follows: the enterprise's energy saving program has a number of design alternatives: $X_{1}$-Introduction of metering and monitoring of coolant losses. $X_{2}-$ Preventive network testing. Breakthrough elimination. $X_{3}$ - Replacing physically worn insulation. Insulating network wire insulation.

These project alternatives are evaluated by criteria: $R_{1}$ is payback $<3 ; R_{2}$ is value of excess water costs for $1 \mathrm{UAH}$ finished products; $R_{3}$ is compliance with the technological regime; $R_{4}$ is reducing the loss of energy resources by $1 \mathrm{UAH}$ finished products; $R_{5}$ is reduction of accounts receivable and maturity; $R_{6}$ is improvement of management accounting systems and it is necessary to find the best project alternative on a set of criteria.

1. Build a relationship matrix $R_{1}$. We assume that all relations are transitive, that is, if $x_{2}>x_{1}$, and $x_{3} \approx x_{2}$, that $x_{3}>x_{1}$.

We use the relations:

$$
\mu_{R}\left(x_{i}, x_{j}\right)=\left\{\begin{array}{l}
1, \text { if } a x_{i}>x_{j}, \text { or } x_{i} \approx x_{j} ; \\
0, \text { if } a x_{i}<x_{j},
\end{array}\right.
$$

there is or if get the relationship matrix $R_{1}$ (Table 3), $\omega_{1}=0.23$.

Table 3. $R_{1}$ relationship matrix.

\begin{tabular}{|c|c|c|c|}
\hline$x_{j}$ & $x_{1}$ & $x_{2}$ & $x_{3}$ \\
\cline { 1 - 2 }$x_{i}$ & 1 & 1 & 1 \\
\hline$x_{1}$ & 0 & 1 & 0 \\
\hline$x_{2}$ & 1 & 1 & 1 \\
\hline$x_{3}$ & &
\end{tabular}

2. Similarly, we build the relationship matrix $R_{2}\left(\omega_{2}=0.18\right), R_{3}\left(\omega_{3}=0.14\right), R_{4}\left(\omega_{4}=\right.$ $0.1), R_{5}\left(\omega_{5}=0.19\right), R_{6}\left(\omega_{6}=0.17\right)$.

3. We build the convolution of relations $Q_{1}=R_{1} \cap R_{2} \cap R_{3} \cap R_{4} \cap R_{5} \cap R_{6}$, (Table 4).

Table 4. Relationship convolution.

\begin{tabular}{|c|c|c|c|}
\hline$x_{j}$ & $x_{1}$ & $x_{2}$ & $x_{3}$ \\
\cline { 1 - 2 }$x_{i}$ & 1 & 0 & 0 \\
\hline$x_{1}$ & 0 & 1 & 0 \\
\hline$x_{2}$ & 0 & 0 & 1 \\
\hline$x_{3}$ &
\end{tabular}

4. Find a subset of non-dominated project alternatives:

$$
\begin{aligned}
& \mu_{Q_{1}}^{n d}(x)=1-\sup _{y \in X}\left\{\mu_{Q_{1}}(x, y)-\mu_{Q_{1}}(y, x)\right\} ; \\
& \mu_{Q_{1}}^{n d}\left(x_{1}\right)=1-\sup _{y \in X}\{0-0 ; 0-0\}=1 ; \\
& \mu_{Q_{1}}^{n d}\left(x_{2}\right)=1-\sup _{y \in X}\{0-0 ; 0-0\}=1 ; \\
& \mu_{Q_{1}}^{n d}\left(x_{3}\right)=1-\sup _{y \in X}\{0-0 ; 0-0\}=1 .
\end{aligned}
$$


Get $\mu_{Q_{1}}^{\text {nd }}(x)=[1 ; 1 ; 1]$.

5. Build a Fuzzy Preference Ratio $Q_{2}$ (additive convolution of relations $R_{j}$ ), $Q_{2}=\sum_{j=1}^{m=3} \omega_{j} f_{j}(x)$ its membership function is shown in Table 5.

Table 5. Additive convolution of relations $R_{j}$.

\begin{tabular}{|c|c|c|c|}
\hline$x_{j}$ & $x$ & $x$ & $x$ \\
\hline$x_{i}$ & & & \\
\hline$x_{1}$ & 1 & 0.27 & 0.35 \\
\hline$x_{2}$ & 0.74 & 1 & 0.58 \\
\hline$x_{3}$ & 0.43 & 0.41 & 1 \\
\hline
\end{tabular}

6. Find a subset of non-dominated project alternatives for the relationship $Q_{2}$ :

$$
\begin{aligned}
& \mu_{Q_{2}}^{n d}(x)=1-\sup _{y \in X}\left\{\sum_{j=1}^{m=3} \mu_{Q_{2}}(x, y)-\mu_{Q_{2}}(y, x)\right\} ; \\
& \mu_{Q_{2}}^{n d}\left(x_{1}\right)=1-\sup _{y \in X}\{(0.74-0.27) ;(0.43-0.35)\}=0.92 ; \\
& \mu_{Q_{2}}^{n d}\left(x_{2}\right)=1-\sup _{y \in X}\{(0.27-0.74) ;(0.41-0.58)\}=0,53 ; \\
& \mu_{Q_{2}}^{n d}\left(x_{3}\right)=1-\sup _{y \in X}\{(0.35-0.43) ;(0.58-0.41)\}=0.83 .
\end{aligned}
$$

Get $\mu_{Q_{2}}^{n d}\left(x_{i}\right)=[0.92 ; 0.53 ; 0.83]$.

7. Find the intersection of sets $Q_{1}^{n d}, Q_{2}^{n d}$ and calculate the membership function of the resulting subset $Q_{n d}=Q_{1}^{n d} \cap Q_{2}^{n d}$. Its membership function is equal to $\mu_{Q}^{n d}\left(x_{i}\right)=\min \left\{\mu_{Q_{1}}^{n d}\left(x_{i}\right), \mu_{Q_{2}}^{n d}\left(x_{i}\right)\right\} ; \mu_{Q}^{n d}\left(x_{i}\right)=[0.92 ; 0.53 ; 0.83]$.

Thus, the best choice when making a decision by the project manager for inclusion in the energy saving program will be the project alternative: $X_{1}$ - Introduction of metering and monitoring of coolant losses.

\section{Conclusions}

The results of the research allowed us to improve the toolkit for the project manager when choosing project alternatives in the framework of the energy saving program at the enterprises of the MMC of Ukraine.

The proposed project practice allows the project manager not only to monitor (analyze the state on the "current date"), but to monitor the progress of the energy saving program (to make more informed management decisions when projects are included in the program).

However, there is a need to measure the extent to which a particular project contributes to the achievement of a program goal. Therefore, the list of criteria for the value of project results in the work was turned into an absolute measurement scale; this allowed evaluating each alternative project at the stage of developing a program to minimize the consumption of fuel and energy resources necessary for the production of products (services) of established quality, taking into account the degree of satisfaction of interested parties and limited organization's resources, and risk factors. 
As a result of the results obtained, it was revealed that most of the problems in implementing the energy saving strategy are related to payback issues and a decrease in the loss of fuel and energy resources by $1 \mathrm{UAH}$ finished products. The overall assessment in ranking the goals of the energy saving program (Table 1) ranges from 1.2 to 2.6, which, in turn, is a prerequisite for the use of value-based management in the formation of the program.

It is important to remember that the effectiveness of managerial decision making by a project manager is based on his ability to respond to problems arising during the implementation of projects and programs, and the need to constantly take steps to satisfy all program stakeholders. The process of comparing project alternatives with criteria for the value of their results, as well as the ratio of service quality assessments, helps the project manager to increase the soundness of management decisions and improve the effectiveness of program implementation in general.

As a prospect for further research, it is proposed to develop a methodology for selecting project alternatives in the formation of energy saving programs at enterprises of the mining and metallurgical complex of Ukraine by analogy with the methodology for assessing the level of environmental safety of housing, considered by the authors in [14]. Also, taking into account the presence of a large number of service enterprises for workers of the mining complex, it is possible to take into account recommendations for ensuring safe working conditions, considered in [15] and recommendations for the reconstruction of residential buildings that are located in the departmental territories of this complex [16].

The studies were conducted in the framework of the scientific theme: "Development of innovative development systems based on project and program management" (State registration No. 0112U003646). The authors are grateful for the assistance in the preparation of materials, Dr. Sc., Professor, Dean of the Faculty of the Pridneprovsk State Academy of Civil Engineering and Architecture Bilokon A.I.

\section{References}

1. Aptekar', S.S., \& Ivanova, V.V. (2010). Sovremennye energeticheskie problemy GMK Ukrainy i vozmozhnye puti ikh resheniya. Visnyk Ekonomichnoi Nauky Ukrainy, (1).

2. Finnerty, N., Sterling, R., Coakley, D., Contreras, S., Coffey, R., \& Keane, M.M. (2017). Development of a Global Energy Management System for non-energy intensive multi-site industrial organisations: A methodology. Energy, (136), 16-31. https://doi.org/10.1016/j.energy.2016.10.049

3. Trifonov, I., Cherepovskaya, N., Trifonov, P., Korneeva, I., \& Ksenofontov, A. (2019). Making management decisions based on value criteria when developing programs for energy-intensive enterprises. International Journal of Recent Technology and Engineering, 8(1), 2154-2160.

4. May, G., Stahl, B., Taisch, M., \& Kiritsis, D. (2017). Energy management in manufacturing: From literature review to a conceptual framework. Journal of Cleaner Production, (167), 14641489. https://doi.org/10.1016/j.jclepro.2016.10.191

5. Böttcher, C., \& Müller, M. (2016). Insights on the impact of energy management systems on carbon and corporate performance. An empirical analysis with data from German automotive suppliers. Journal of Cleaner Production, (137), 1449-1457. https://doi.org/10.1016/j.jclepro.2014.06.013

6. Martí-Ballester, C.-P. (2017). Sustainable energy systems and company performance: Does the implementation of sustainable energy systems improve companies' financial performance? Journal of Cleaner Production, (162), S35-S50. https://doi.org/10.1016/j.jclepro.2016.12.015

7. May, G., Stahl, B., \& Taisch, M. (2016). Energy management in manufacturing: Toward ecofactories of the future - A focus group study. Applied Energy, (164), 628-638. https://doi.org/10.1016/j.apenergy.2015.11.044 
8. Trachuk, A.V., \& Linder, N.V. (2018). Technologies of the distributed generation: empirical evaluations of the innovations acceptance. Strategic Decisions and Risk Management, (1), 32-48. https://doi.org/10.17747/2078-8886-2018-1-32-48

9. Abrell, J., \& Weigt, H. (2012). Combining energy networks. Networks and Spatial Economics, 12(3), 377-401.

10. Finnerty, N., Contreras, S., Sterling, R., Coakley, D., \& Keane, M. (2017). Defining Corporate Energy Policy and Strategy to Achieve Carbon Emissions Reduction in Non-Energy Intensive Multi-Site Industrial Organizations. Energy Management and Policies. https://doi.org/10.18690/978-961-286-051-6.1

11. Belokon', A.I., \& Trifonov, I.V. (2012). Snizhenie neopredelennosti pri formirovanii i realizatsii programm razvitiya organizatsiy. Stroitel'stvo, materialovedenie, mashinostroenie. Seriya: Starodubovskie chteniya, (64), 335-339.

12. Wang, L., Peng, J., \& Wang, J. (2018). A multi-criteria decision-making framework for risk ranking of energy performance contracting project under picture fuzzy environment. Journal of Cleaner Production, (191), 105-118. https://doi.org/10.1016/j.jclepro.2018.04.169

13. Orlovskiy S.A. (1981). Problemy prinyatiya resheniy pri nechetkoy iskhodnoy informatsii. Moskva: Nauka.

14. Sankov, P., Trifonov, I., Tkach, N., Hilov, V., Bakharev, V., Tretyakov, O., \& Nesterenko, S. (2017). Development of the method of evaluation of the level of environmental safety of housing accommodation and its approbation. Eastern-European Journal of Enterprise Technologies, 4(10(88)), 61-69. https://doi.org/10.15587/1729-4061.2017.108443

15. Sankov, P.M., Tkach, N.O., Dikarev, K.B., Blyzniuk, A.M., \& Hvadzhaia, B.D. (2018). Effect of Motor Transport on the Working Places in the Service Infrastructure (by Noise Factor and Urban Air Pollution in the Center of the Dnipro City). Science and Innovation, 14(3), 59-66. https://doi.org/10.15407/scine14.03.059

16. Zakharov, Y.I., Sankov, P.M., Trifonov, I.V., Tkach, N.O., \& Toshyna, L.O. (2019). The Content and Specific Features of Reconstructing the Residential Houses of Various Configurations. Science and Innovation, 15(3), 79-90. https://doi.org/10.15407/scine15.03.079 